\title{
Identification of key genes and microRNAs involved in kidney Wilms tumor by integrated bioinformatics analysis
}

\author{
LEI ZHANG $^{1 *}$, XIAN GAO $^{2 *}$, XIANG ZHOU $^{1 *}$, ZHIQIANG ${ }^{1}{ }^{1}$, YI WANG $^{1}$, \\ RAN LI ${ }^{1}$, MIN TANG ${ }^{1}$, WEI WANG $^{1}$ and WEI ZHANG ${ }^{1}$ \\ Departments of ${ }^{1}$ Urology and ${ }^{2}$ Oncology, The First Affiliated Hospital of Nanjing Medical University, \\ Nanjing, Jiangsu 210029, P.R. China
}

Received November 23, 2018; Accepted June 27, 2019

DOI: $10.3892 /$ etm.2019.7870

\begin{abstract}
Wilms tumor (WT) is one of the most common types of pediatric solid tumors; however, its molecular mechanisms remain unclear. The present study aimed to identify key genes and microRNAs (miRNAs), and to predict the underlying molecular mechanisms of WT using integrated bioinformatics analysis. Original gene expression profiles were downloaded from the Gene Expression Omnibus (GEO; accession, GSE66405) and The Cancer Genome Atlas (TCGA) databases. Similarly, miRNA expression patterns were downloaded from GEO (accession, GSE57370) and TCGA. R version 3.5.0 software was used to identify differentially expressed genes (DEGs) and differentially expressed miRNAs (DEMs) using the limma and edgeR packages. Kyoto Encyclopedia of Genes and Genomes pathway and Gene Ontology analyses were performed to examine the biological functions of the DEGs. Additionally, a protein-protein interaction (PPI) network was constructed to screen hub gene modules using Cytoscape software. By predicting target genes of the DEMs and integrating them with DEGs, the present study constructed a miRNA-mRNA regulatory network to predict the possible molecular mechanism of WT. Expression of hub genes was validated using the Oncomine database. A total of 613 genes and 29 miRNAs were identified to be differentially expressed in WT. By constructing a PPI network and screening hub gene modules, 5 upregulated genes, including BUB1 mitotic checkpoint serine/threonine kinase, BUB1B mitotic checkpoint serine/threonine kinase $\mathrm{B}$, cell division cycle protein 45 , cyclin B2 and pituitary tumor-transforming 1 . These genes
\end{abstract}

Correspondence to: Dr Wei Zhang or Dr Wei Wang, Department of Urology, The First Affiliated Hospital of Nanjing Medical University, 300 Guangzhou Road, Nanjing, Jiangsu 210029, P.R. China

E-mail: zhangwei_urology@sina.com

E-mail: 13675132117@163.com

*Contributed equally

Key words: Wilms tumor, differentially expressed genes, microRNA, bioinformatics were identified to be associated with the cell cycle pathway, which suggested that these genes may serve important roles in WT. In addition, a miRNA-mRNA regulatory network was constructed and comprised 16 DEMs and 19 DEGs. In conclusion, key genes, miRNAs and the mRNA-miRNA regulatory network identified in the present study may improve understanding of the underlying molecular mechanisms in the occurrence and development of WT, and may aid the identification of potential biomarkers and therapeutic targets.

\section{Introduction}

Wilms tumor (WT) is one of the most common types of pediatric solid tumor, with a prevalence of 1 in 10,000 children worldwide (1). WT typically occurs in healthy children; however, $\sim 10 \%$ of children who have congenital anomalies, including Denys-Drash syndrome and Beckwith-Wiedemann syndrome, have been reported to exhibit a predisposition to this type of cancer $(2,3)$. WT is an embryological tumor that is composed of a variable mixture of stromal, blastemal and epithelial elements and is histologically similar to renal embryogenesis (4). It has been verified that certain genetic mutations, including those in Wilms tumor 1 (WT1), Wilms tumor on the X (WTX) and catenin b1 (CTNNB1), are associated with WT susceptibility (5-7). WT1 is closely associated with renal development and its mutations account for $20 \%$ of WT cases (8). It has been identified from a large number of WT cases that CTNNB1 mutations overlap with the WT1 mutation while the WTX mutation is predominantly mutually exclusive (9). Furthermore, a number of studies have suggested the involvement of various genes and cellular signaling pathways in the occurrence and development of WT $(10,11)$. A previous study indicated that KRAS mutations participate in the WT occurrence by activating the PI3K/AKT pathway (12). However, the definite molecular mechanisms remain unknown. Therefore, it is necessary to study the underlying molecular mechanisms of WT to prevent tumorigenesis and develop effective therapeutic measures.

MicroRNAs (miRNAs/miRs) are a class of small non-coding RNAs that regulate gene expression by post-transcriptionally binding to the $3^{\prime}$ untranslated region of target mRNAs, inducing mRNA degradation or silencing (13). In previous decades, a large number of miRNAs have been 
identified in humans and numerous previous studies have demonstrated their role of acting as oncogenes or tumor suppressors by regulating tumor occurrence, progression and survival $(14,15)$. For example, Zhu et al (16) reported that miR-92a-3p suppresses the proliferation, migration and invasion of WT cells by modulating the NOTCH1 signaling pathway. Therefore, identification of differentially expressed miRNAs (DEMs) has been demonstrated to be a promising strategy in the identification of novel biomarkers for the early diagnosis or prognosis of WT.

Application of microarray analysis or high-throughput sequencing can quickly identify differentially expressed genes (DEGs) and DEMs in tumor samples, and these are promising techniques in clinical research, including molecular classification, targeted drug discovery and survival prediction $(17,18)$. The present study identified DEGs in WT using the GSE66405 dataset from the Gene Expression Omnibus (GEO) database and data from The Cancer Genome Atlas (TCGA) database (19). Additionally, analysis of DEMs was performed using the GSE57370 dataset and TCGA database (20). Overall, the present study aimed to provide information that would promote the understanding of the molecular mechanisms of WT.

\section{Materials and methods}

Raw data. All datasets used in the present study were downloaded from the GEO (https://www.ncbi.nlm.nih.gov/geo/) and TCGA (https://cancergenome.nih.gov/) databases (21). The GSE66405 dataset includes mRNA expression profiles of $28 \mathrm{WT}$ and four paracancerous normal samples, which were determined using the Agilent-039494 SurePrint G3 Human GE v2 8x60K (GPL17077) platform (17). The GSE57370 dataset includes miRNA expression profiles of $62 \mathrm{WT}$ and four paracancerous normal samples, which were determined using the Agilent-031181 Unrestricted_Human miRNA_V16.0_Microarray (GPL16770)platform(18).In addition, further mRNA and miRNA expression profiles were downloaded from the TCGA WT datasets (mRNA, https://portal.gdc.cancer. gov/repository?facetTab $=$ files $\&$ filters $=\% 7 \mathrm{~B} \% 22 \mathrm{op} \% 22 \% 3 \mathrm{~A} \%$ 22and $\% 22 \% 2 \mathrm{C} \% 22$ content $\% 22 \% 3 \mathrm{~A} \% 5 \mathrm{~B} \% 7 \mathrm{~B} \% 22 \mathrm{op} \% 22 \% 3 \mathrm{~A} \%$ 22 in $\% 22 \% 2 \mathrm{C} \% 22$ content $\% 22 \% 3 \mathrm{~A} \% 7 \mathrm{~B} \% 22$ field $\% 22 \% 3 \mathrm{~A} \% 2$ 2cases.project.project_id $\% 22 \% 2 \mathrm{C} \% 22$ value $\% 22 \% 3 \mathrm{~A} \% 5 \mathrm{~B} \% 22 \mathrm{~T}$ ARGET-WT\%22\%5D\%7D\%7D\%2C\%7B\%22op $\% 22 \% 3 \mathrm{~A} \% 22 \mathrm{i}$ n $\% 22 \% 2 \mathrm{C} \% 22$ content $\% 22 \% 3 \mathrm{~A} \% 7 \mathrm{~B} \% 22$ field $\% 22 \% 3 \mathrm{~A} \% 22$ files. analysis.workflow_type $\% 22 \% 2 \mathrm{C} \% 22$ value $\% 22 \% 3 \mathrm{~A} \% 5 \mathrm{~B} \% 22 \mathrm{H}$ TSeq\%20-\%20Counts\%22\%5D\%7D\%7D\%2C\%7B\%22op\%22 $\% 3 \mathrm{~A} \% 22 \mathrm{in} \% 22 \% 2 \mathrm{C} \% 22$ content $\% 22 \% 3 \mathrm{~A} \% 7 \mathrm{~B} \% 22$ field $\% 22 \% 3 \mathrm{~A}$ $\% 22$ files.experimental_strategy $\% 22 \% 2 \mathrm{C} \% 22$ value $\% 22 \% 3 \mathrm{~A} \% 5$ B\%22RNA-Seq\%22\%5D\%7D\%7D\%5D\%7D; miRNA, https:// portal.gdc.cancer.gov/repository? facetTab $=$ files \& filters $=\% 7 \mathrm{~B} \% 2$ 2op $\% 22 \% 3 \mathrm{~A} \% 22$ and $\% 22 \% 2 \mathrm{C} \% 22$ content $\% 22 \% 3 \mathrm{~A} \% 5 \mathrm{~B} \% 7 \mathrm{~B} \% 2$ 2op $\% 22 \% 3 \mathrm{~A} \% 22 \mathrm{in} \% 22 \% 2 \mathrm{C} \% 22$ content $\% 22 \% 3 \mathrm{~A} \% 7 \mathrm{~B} \% 22$ field $\% 22 \% 3 \mathrm{~A} \% 22$ cases.project.project_id $\% 22 \% 2 \mathrm{C} \% 22$ value $\% 22 \% 3$ A\%5B \%22TARGET-WT\%22\%5D\%7D\%7D\%2C\%7B\%22op \% $22 \% 3 \mathrm{~A} \% 22 \mathrm{in} \% 22 \% 2 \mathrm{C} \% 22$ content $\% 22 \% 3 \mathrm{~A} \% 7 \mathrm{~B} \% 22$ field $\% 22 \%$ 3A $\% 22$ files.data_category $\% 22 \% 2 \mathrm{C} \% 22$ value $\% 22 \% 3 \mathrm{~A} \% 5 \mathrm{~B} \% 22$ Transcriptome $\% 20$ Profiling\%22\%5D\%7D\%7D\%2C\%7B\%22op $\% 22 \% 3 \mathrm{~A} \% 22$ in $\% 22 \% 2 \mathrm{C} \% 22$ content $\% 22 \% 3 \mathrm{~A} \% 7 \mathrm{~B} \% 22$ field $\% 22$ $\% 3 \mathrm{~A} \% 22$ files.data_type $\% 22 \% 2 \mathrm{C} \% 22$ value $\% 22 \% 3 \mathrm{~A} \% 5 \mathrm{~B} \% 22 \mathrm{~m}$ iRNA\%20Expression\%20Quantification $\% 22 \% 5 \mathrm{D} \% 7 \mathrm{D} \% 7 \mathrm{D} \% 2 \mathrm{C}$ \%7B\%22op\%22\%3A\%22in\%22\%2C\%22content $\% 22 \% 3 \mathrm{~A} \% 7 \mathrm{~B} \%$ 22field $\% 22 \% 3 \mathrm{~A} \% 22$ files.experimental_strategy $\% 22 \% 2 \mathrm{C} \% 22 \mathrm{va}$ lue $\% 22 \% 3 \mathrm{~A} \% 5 \mathrm{~B} \% 22 \mathrm{miRNA}-\mathrm{Seq} \% 22 \% 5 \mathrm{D} \% 7 \mathrm{D} \% 7 \mathrm{D} \% 5 \mathrm{D} \% 7 \mathrm{D}$ \&searchTableTab=files), which included 6 paracancerous normal renal tissues and 126 or 132 tumor samples, respectively.

Identification of DEGs and DEMs. The R 3.5.0 software (https://www.r-project.org/) was used to identify the DEGs between WT and normal samples in the GSE66405 dataset using the limma package with the following cut-off criteria: Fold change $(\mathrm{FC})>2$ and $\mathrm{P}<0.05$ (22). Additionally, the DEGs in the TCGA WT dataset were determined using the edgeR package with FC $>2$ and a false discovery rate (FDR) adjusted $\mathrm{P}<0.05$ as the cut-off criteria (23). Similarly, DEMs were screened with $\mathrm{FC}>1$ and $\mathrm{P}<0.05$ in GSE57370, and FC $>1$ and FDR adjusted $\mathrm{P}<0.05$ in the TCGA dataset. The limma and edgeR packages were installed using Bioconductor version 3.7 (https://www.bioconductor.org/).

Gene Ontology (GO) and pathway enrichment analysis. The Database for Annotation, Visualization and Integrated Discovery (DAVID 6.8; http://david.abcc.ncifcrf.gov/) was used to perform GO and Kyoto Encyclopedia of Genes and Genomes (KEGG) pathway enrichment analyses of the DEGs. $\mathrm{P}<0.05$ was considered to indicate a statistically significant result (24).

Protein-protein interaction (PPI) network construction and module analysis. The Search Tool for the Retrieval of Interacting Genes (STRING 11.0; http://string.embl.de/) database was used to obtain PPI information for the DEGs, and interactions with a combined score $>0.7$ were considered as significant protein pairs (25). Subsequently, Cytoscape 3.6.1 software was used to visualize the PPI network and Molecular Complex Detection (MCODE) was used to screen central modules of the network with the following cut-off criteria: Degree $=2$, node score cut-off $=0.2, \mathrm{k}$-score $=2$ and maximum depth=100 $(26,27)$.

Validation of hub genes. Oncomine (https://www.oncomine. org), an online microarray database, was utilized to collect and analyze gene expression data for tumor and paracarcinoma normal samples. The Yusenko et al (28) renal dataset was used to verify the differential expression of hub genes between four WT and five normal renal samples. The $\log 2$ median-centered intensity value was visualized by GraphPad Prism 5.0 software (GraphPad Software, Inc.).

Prediction of miRNA targets. Target genes of the DEMs in the GSE57370 dataset and TCGA dataset were predicted using TargetScan (http://www.targetscan.org/vert_72/), miRTarBase (http://mirtarbase.mbc.nctu.edu.tw/php/index.php) and miRDB (http://mirdb.org/). Only targets identified by all three databases were further analyzed by comparing them with previously identified DEGs (29). Furthermore, the predicted mRNA-miRNA regulatory interactions were visualized using Cytoscape version 3.6.1.

\section{Results}

Identification of common DEGs in GSE66405 and TCGA. A total of 996 DEGs in GSE66405 were identified according to the aforementioned cut-off criteria, including 280 upregulated and 716 downregulated genes (Fig. 1A; Table SI). In addition, 
A

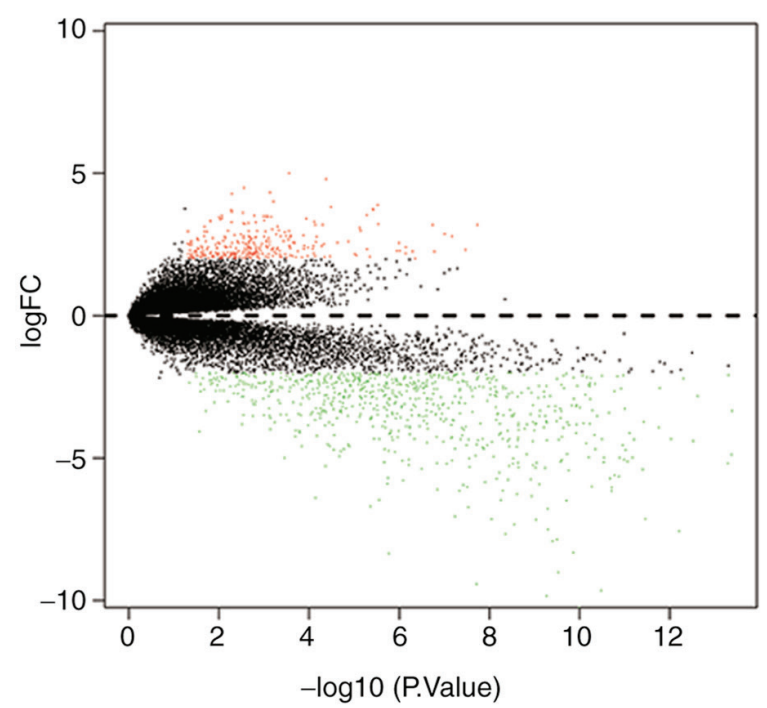

C

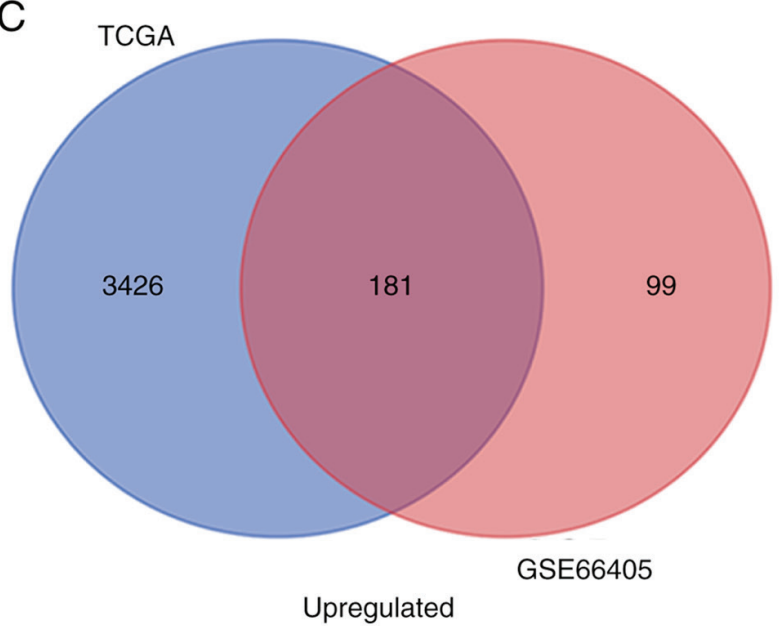

B

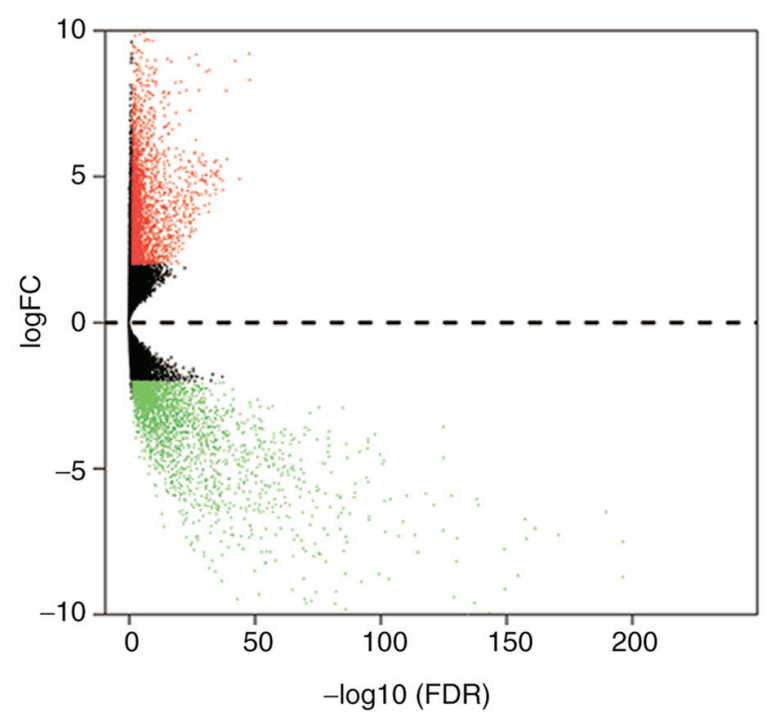

D

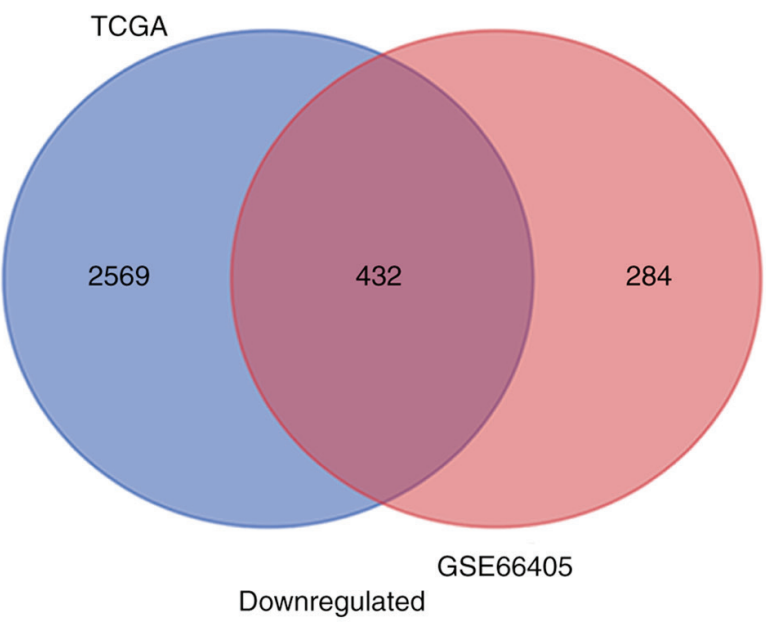

Figure 1. Identification of DEGs in gene expression profiling datasets. (A) A total of 996 DEGs were identified in GSE66405. (B) A total of 6,608 DEGs were identified in TCGA dataset. Red, upregulated DEGs; Blue, downregulated DEGs. (C) There were 181 upregulated common DEGs of the two datasets. (D) There were 432 downregulated common DEGs of the two datasets. DEG, differentially expressed gene; FC, fold change; FDR, false discovery rate; TCGA, The Cancer Genome Atlas.

6,608 DEGs were identified in the TCGA dataset, including 3,607 upregulated and 3,001 downregulated genes (Fig. 1B; Table SII). A Venn diagram was used to present the overlapping 181 upregulated and 432 downregulated genes identified in both datasets (Fig. 1C and D).

GO term and KEGG pathway enrichment analysis of DEGs. To gain further insights into the function and mechanisms of WT, the identified common DEGs were uploaded to DAVID to perform GO and KEGG pathway enrichment analyses. The top 10 terms of each analysis with the lowest P-values are presented in Fig. 2. According to KEGG pathway analysis, the DEGs were predominantly enriched in the 'Metabolic pathway'. In addition, certain DEGs were significantly involved in 'peroxisome proliferator-activated receptor (PPAR) signaling pathway' and 'Protein digestion and absorption'. GO biological process terms revealed that the DEGs were primarily enriched in 'response to drug', 'ion transmembrane transport' and 'excretion'. At the cellular component level, the DEGs were mainly enriched in 'integral component of membrane', 'extracellular exosome' and 'plasma membrane'. At the molecular function level, the DEGs predominantly served a role in 'transporter activity' and 'heparin binding'.

PPI network analysis. All 613 common DEGs were mapped into a PPI network using the STRING online database and the network was visualized using Cytoscape (Fig. S1). BUB1 mitotic checkpoint serine (BUB1) was identified as the gene with the highest degree in the overall network, with a degree of 33. Fig. 3 presents the most significant gene module of the PPI network, which included 28 genes with 366 edges. In addition, key pathways and GO terms of these hub genes are presented in Fig. 4 and Table SIII. These hub genes were predominantly involved in the cell cycle [BUB1, BUB1B mitotic checkpoint serine/threonine kinase B (BUB1B), cell division cycle protein 45 (CDC45), cyclin B2 (CCNB2) and pituitary tumor-transforming 1 (PTTG1)] and oocyte meiosis pathways (BUB1, CCNB2 and PTTG1). Furthermore, BUB1 
A

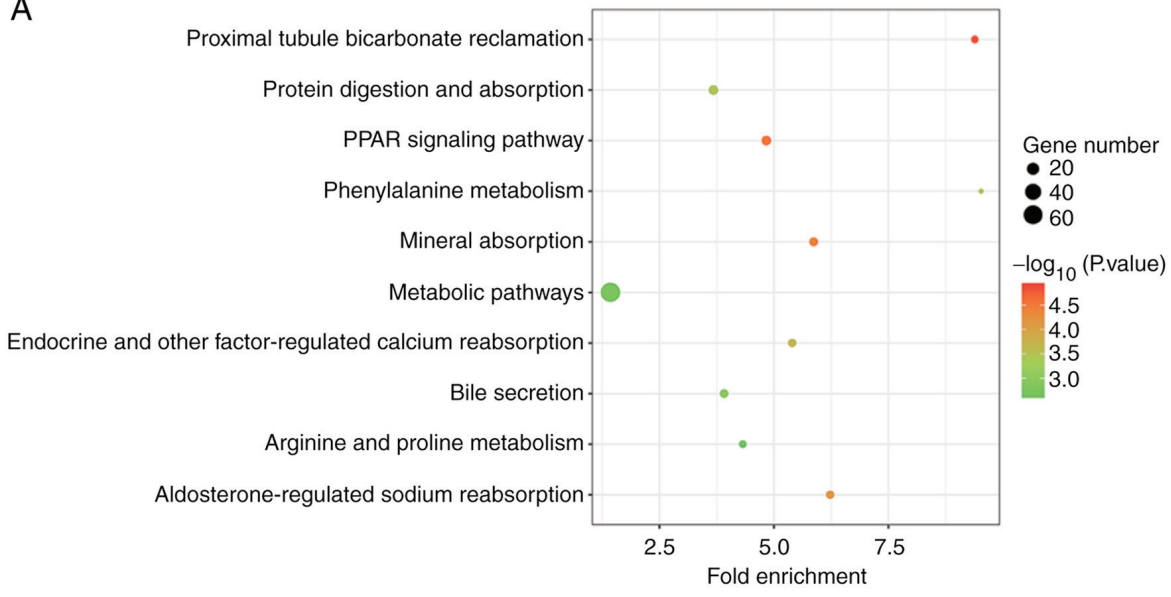

B

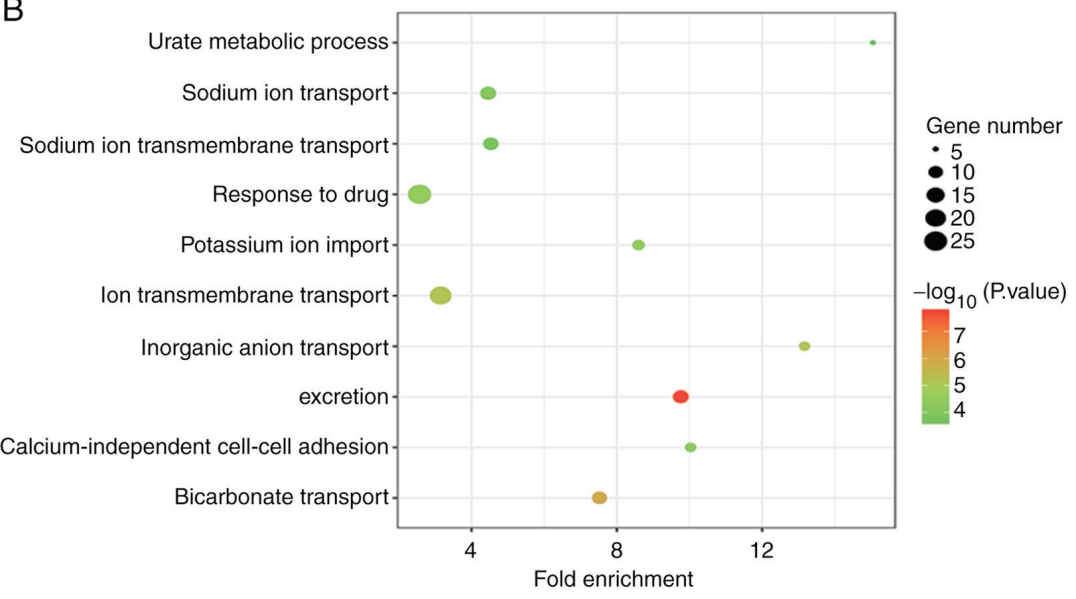

C
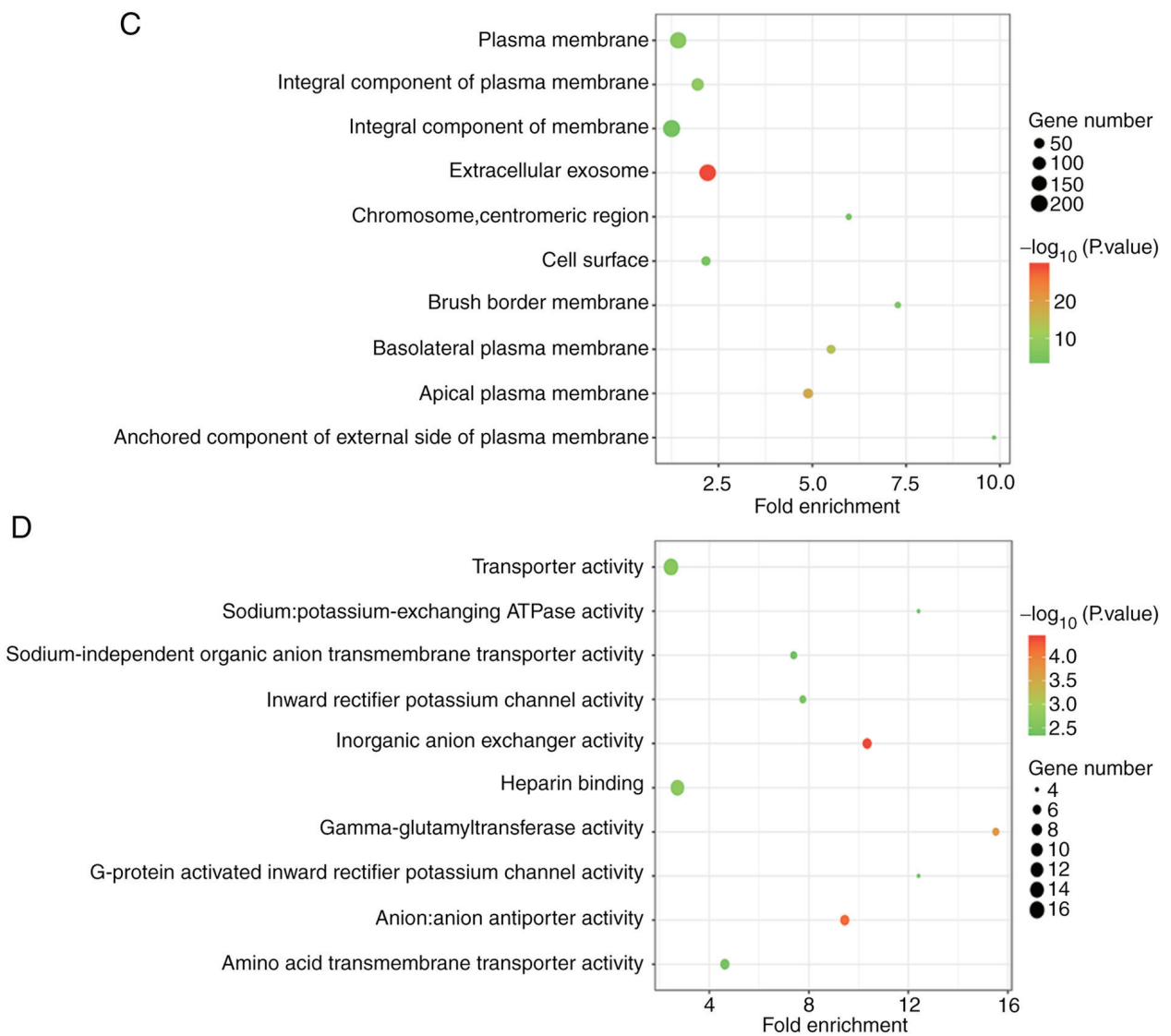

Figure 2. Kyoto Encyclopedia of Genes and Genomes pathway and Gene Ontology term analyses of overlapping differentially expressed genes. (A) Top 10 enriched pathways. (B) Top 10 enriched biological process terms. (C) Top 10 enriched cellular component terms. (D) Top 10 enriched molecular function terms. PPAR, peroxisome proliferator-activated receptor. 


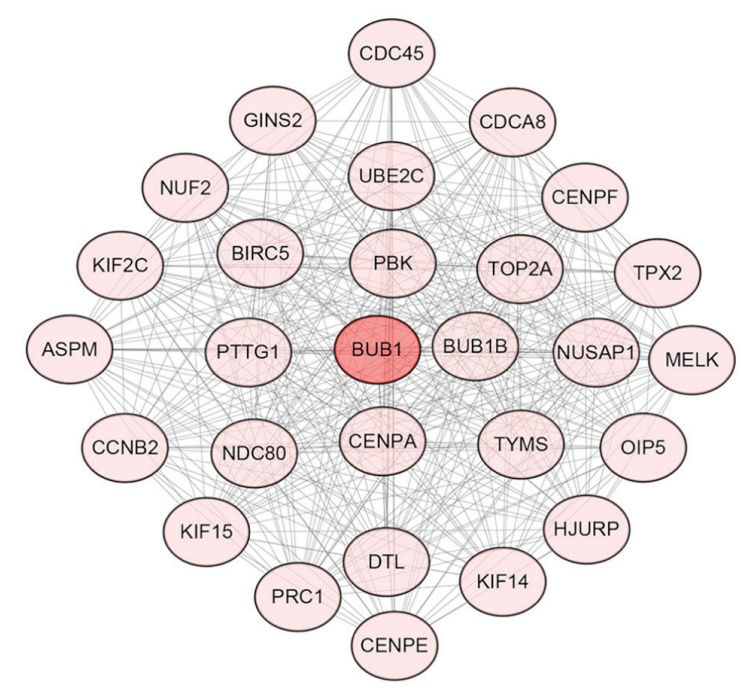

Figure 3. Hub gene module in the protein-protein interaction network with 28 genes. Nodes represent genes and lines represent interactions. BUB1 was marked in deep red as this is the gene with the highest degree.

was revealed to be involved in all of the GO terms identified. As a result, BUB1 was considered to be a central hub gene.

Validation of hub genes in the cell cycle pathway. To further validate the results, the present study examined the expression levels of five hub genes (BUB1, BUB1B, CDC45, CCNB2 and PTTG1) using the Oncomine database. As indicated by the Yusenko Renal dataset, all five genes were significantly upregulated in tumor samples compared with in normal samples $(\mathrm{P}<0.05$; Fig. 5). This suggested that dysregulation of the cell cycle pathway, as well as alterations in the mRNA expression levels of these genes, may be closely associated with WT.

Identification of common DEMs in GSE57370 and the TCGA dataset. A total of 79 and 167 DEMs were identified using the GSE57370 and TCGA datasets, respectively, including 26 and 101 upregulated, and 53 and 66 downregulated miRNAs, respectively (Fig. 6A and B; Tables SIV and SV). Venn diagrams present the 29 overlapping miRNAs, which included 6 upregulated and 23 downregulated miRNAs (Fig. 6C and D).

Prediction of a regulatory network of DEMs-DEGs. A total of 879 target genes of the 6 upregulated and 23 downregulated miRNAs were predicted by the TargetScan, miRTarBase and miRDB databases. Among the 879 genes, 19 were identified to overlap with the identified DEGs (29-31). Subsequently, the present study constructed a potential regulatory network of the DEMs-DEGs, which was visualized using Cytoscape (Fig. 7). In addition, Table SVI presents the GO term and KEGG pathway enrichment analyses of the 19 overlapping genes. Among these genes, Wiskott-Aldrich syndrome protein family member 3 (WASF3) and MARCKS like 1 (MARCKSL1) were enriched in the ' $\mathrm{Fc}$ gamma R-mediated phagocytosis pathway'. Subsequently, the present study validated their expression using Oncomine and the Yusenko Renal dataset and revealed that the two genes were overexpressed in WT compared with in the normal group. When referring to the expression profile of DEMs and the miRNA-mRNA network, downregulated hsa-miR-200b,
hsa-miR-429 and hsa-miR-30c-2 may be the upstream regulatory elements of WASF3 and MARCKSL1 (Fig. 8).

\section{Discussion}

WT is a serious threat to the health of children and develops as a result of abnormalities of various genes which are normally responsible for cellular growth, proliferation and differentiation $(32,33)$. It has been reported that $~ 5 \%$ of children have mutations in WT1 or epigenetic defects at chromosome 11p15, which are predispositions for WT $(5,34)$. In previous decades, a number of genes, including CTNNB1, WTX and tumor protein p53, have been reported to be involved in the tumorigenesis and progression of WT (35-37). Therefore, identification of key genes is vital for understanding the pathogenesis and abnormal biological behavior of WT, and to identify novel therapeutic targets of WT.

First, the present study analyzed available microarray and RNA-sequencing data from the GEO and TCGA databases to identify significant DEGs and DEMs, and 613 significant DEGs were selected by bioinformatics analysis. DAVID was used to perform further analysis of these DEGs to identify their potential associated cellular signaling pathways and functions. KEGG pathway analysis revealed that 65 DEGs of WT were enriched in 'Metabolic pathways', 12 were enriched in the 'PPAR signaling pathway' and 12 were enriched in 'Protein digestion and absorption'. GO term analysis indicated that DEGs were involved in the 'response to drug', 'ion transmembrane transport' and 'excretion' biological processes terms. Furthermore, the DEGs were demonstrated to serve a role in 'transporter activity' and 'heparin binding' at the molecular function level.

Subsequently, according to PPI network construction and module analysis, a hub gene module was identified. This hub gene module contained 28 upregulated genes, and BUB1 was considered as the central gene. BUB1 was identified as the gene with the highest degree (33) in the network, while centromere protein $\mathrm{A}$, ubiquitin conjugating enzyme E2 C and kinesin family member $2 \mathrm{C}$ each had a degree of 32 . KEGG and GO analyses demonstrated that these 28 hub genes were mainly involved in 'Cell cycle' and 'Oocyte meiosis pathway', and were also associated with multiple processes of mitosis according to the molecular biological function terms. Expression validation based on the Oncomine database was performed to investigate the expression levels of BUB1, BUB1B, CDC45, CCNB2 and PTTG1, which were all associated with the 'Cell cycle pathway'. As expected, all five genes were upregulated in tumor tissues compared with in normal samples. Therefore, it may be hypothesized that disorders of the cell cycle pathway and associated genes may contribute to the occurrence of WT.

Cell cycle progression consists of five known phases: $\mathrm{G}_{0}$ (gap 0), $\mathrm{G}_{1}$ (gap 1), $\mathrm{S}$ (DNA synthesis), $\mathrm{G}_{2}$ (gap 2) and $\mathrm{M}$ (mitosis) phase. A number of checkpoints function between these phases to ensure that the integrity of cellular components and the fidelity of DNA synthesis are monitored (38). As is well understood, an abnormal distribution of cells throughout the cell cycle is a hallmark of human cancer, due to accumulating alterations of genes in the cell cycle pathway possibly resulting in impaired abilities of cell division, cell proliferation and response to DNA damage $(39,40)$. BUB1, a mitotic checkpoint protein, has been demonstrated 


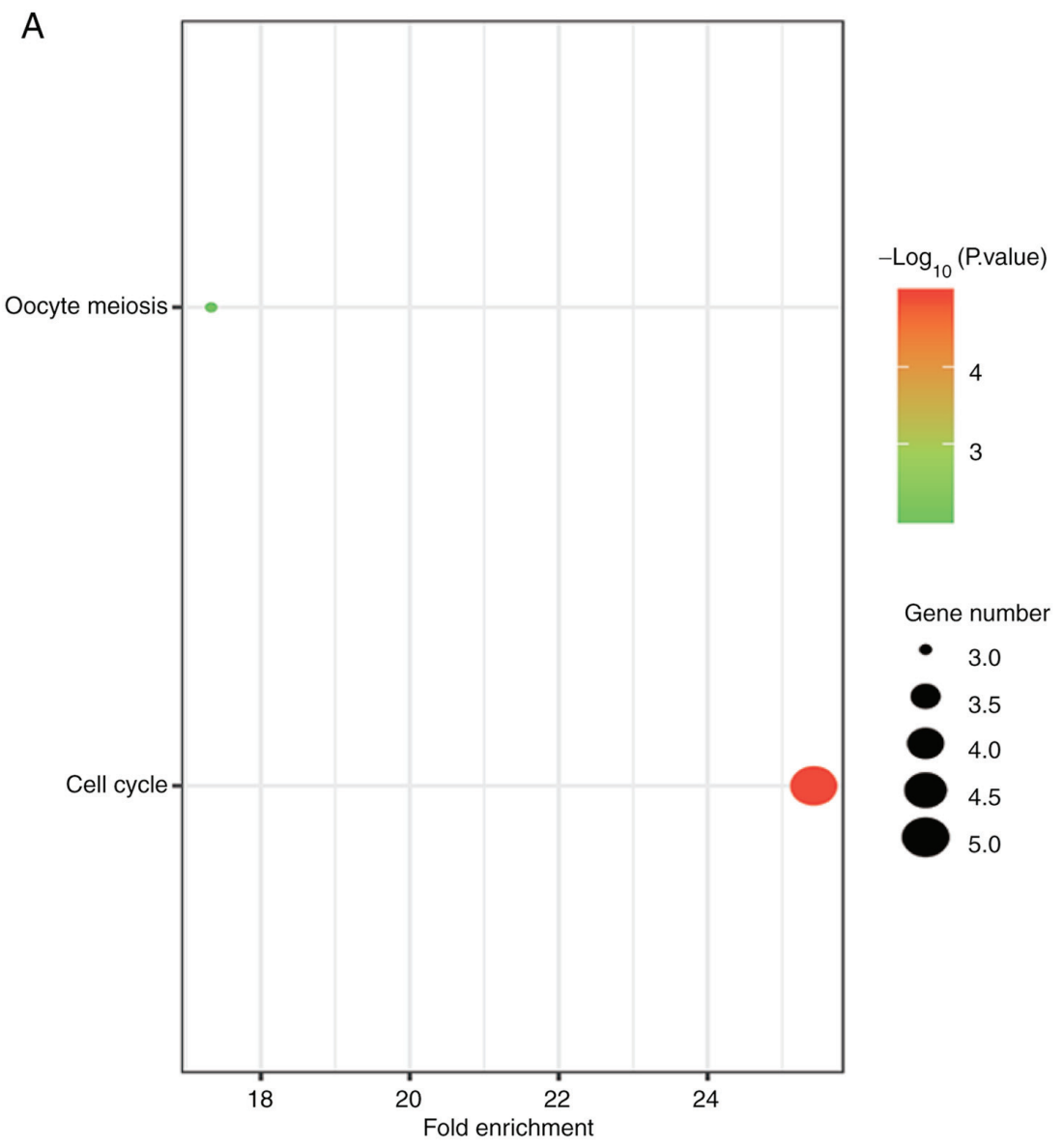

B

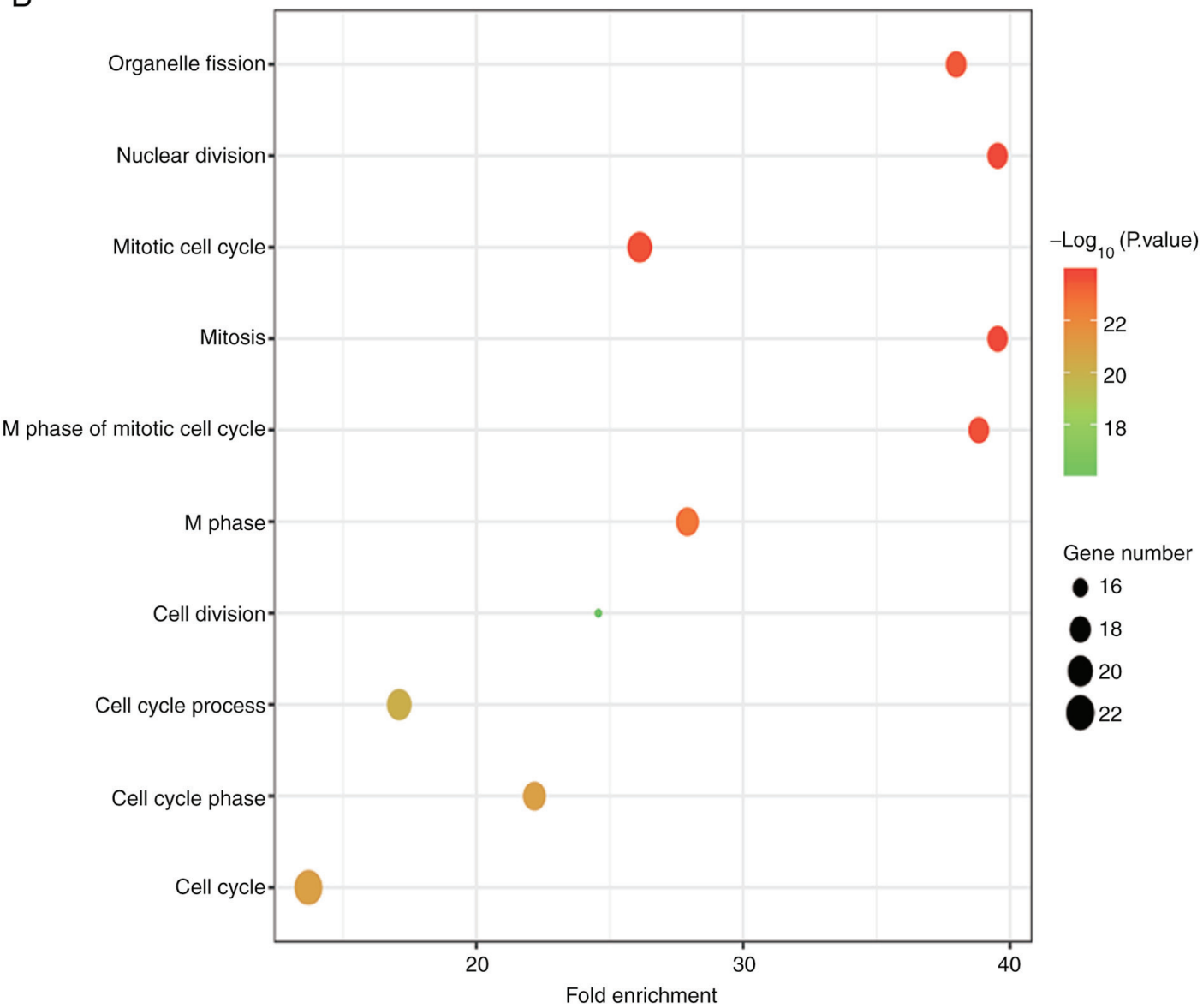

Figure 4. Kyoto Encyclopedia of Genes and Genomes pathway and Gene Ontology term analyses of the 28 hub genes. (A) Enriched pathways. (B) Top 10 enriched biological process terms. 

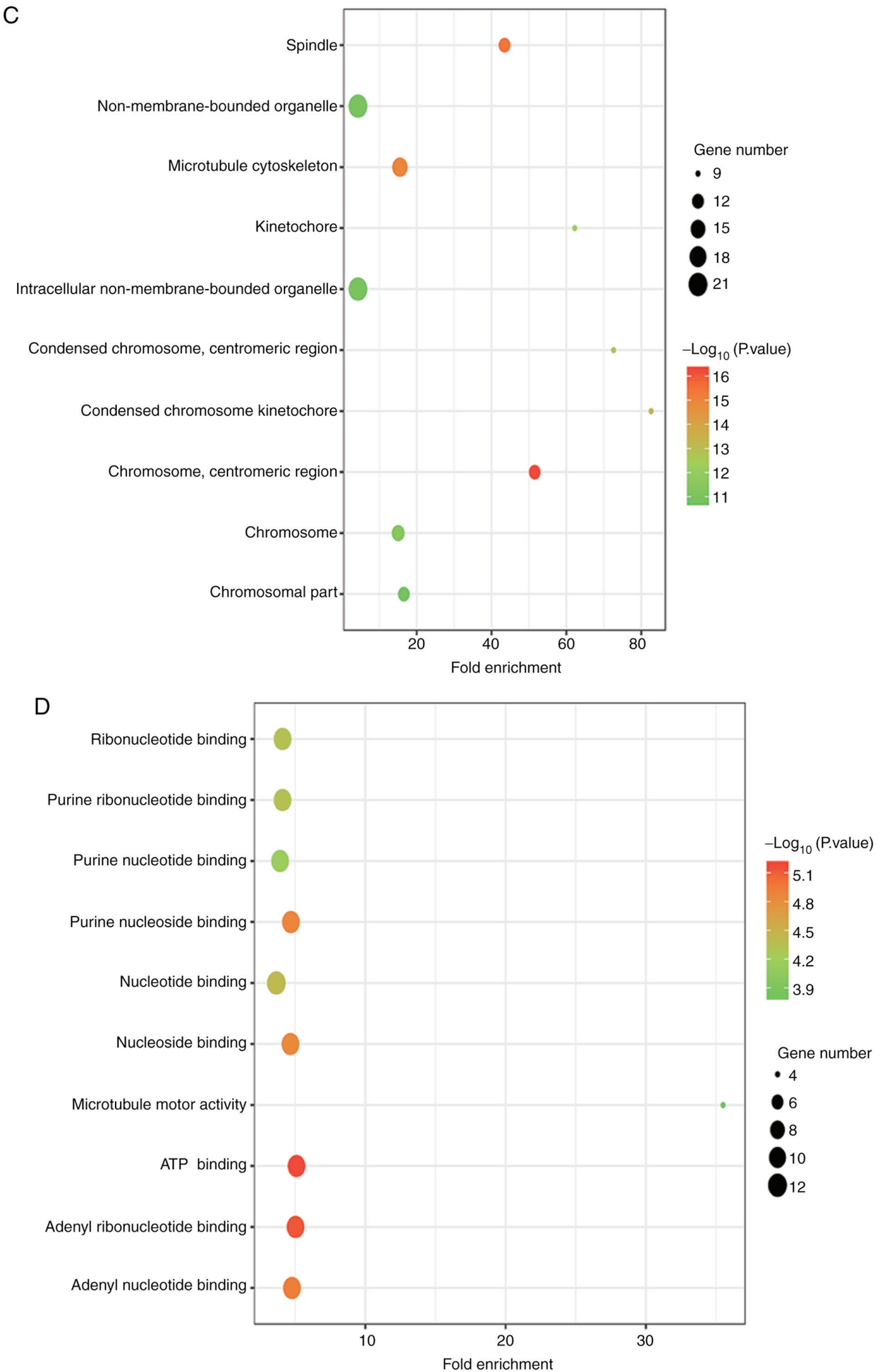

Figure 4. Continued. (C) Top 10 enriched cellular component terms. (D) Top 10 enriched molecular function terms.

to be overexpressed in various types of cancer, such as hepatocellular carcinoma and prostate cancer, and has been associated with the proliferation, migration and invasion of tumor cells $(41,42)$. Furthermore, a number of studies have suggested that BUB1 may be a biomarker for the clinical prognosis of numerous types of tumor, including breast and gastric cancer $(43,44)$. Therefore, it is worth investigating the role of BUB1 in WT further. 

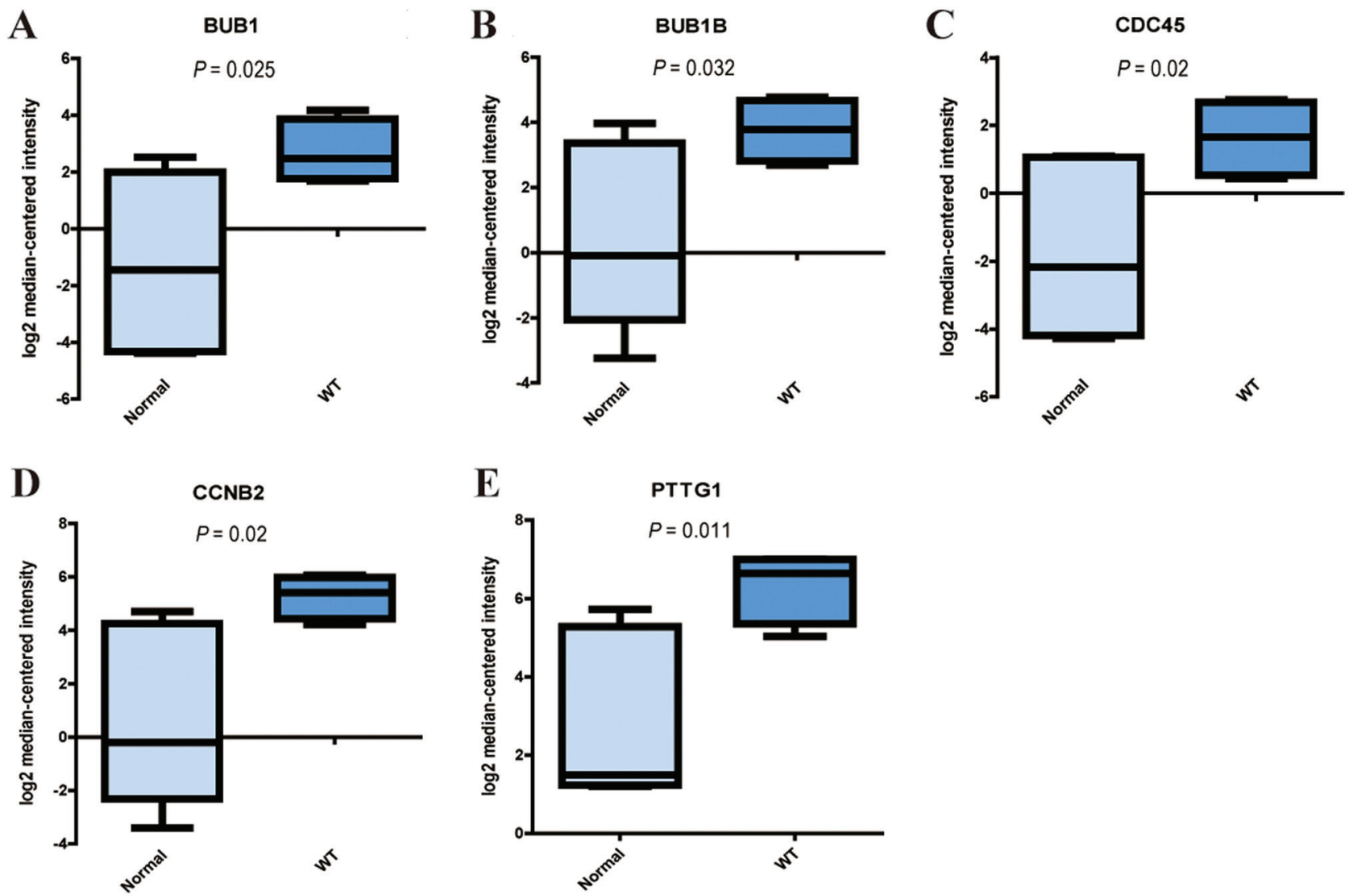

Figure 5. Validation of gene expression based on the Oncomine database. Gene expression of (A) BUB1, (B) BUB1B, (C) CDC45, (D) CCNB2 and (E) PTTG1. BUB1, mitotic checkpoint serine/threonine kinase; BUB1B, mitotic checkpoint serine/threonine kinase B; CCNB2, cyclin B2; CDC45, cell division cycle protein 45; PTTG1, pituitary tumor-transforming 1; WT, Wilms tumor.
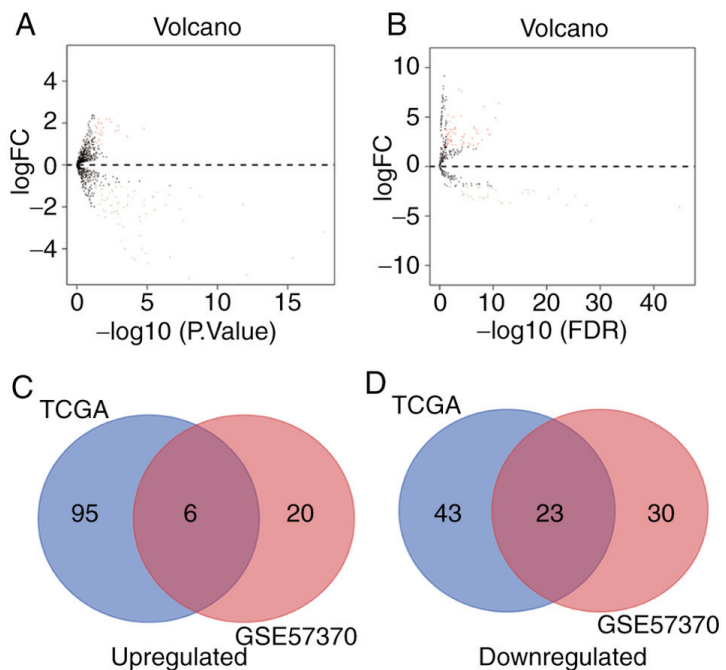

Figure 6. Identification of DEMs in microRNA expression profiling datasets. (A) A total of 79 DEMs were identified in GSE57370. (B) A total of 167 DEMs were identified in TCGA dataset. (C) There were 6 upregulated common DEMs of the two datasets. (D) There were 23 downregulated common DEMs of the two datasets. DEM, differentially expressed microRNA; FC, fold change; FDR, false discovery rate; TCGA, The Cancer Genome Atlas.

miRNAs are popularly applied in the diagnosis and clinical prognosis of various types of tumor due to their regulatory role of mRNAs, which affects the malignant behavior of tumor cells $(45,46)$. In addition, due to an increasing amount of attention for miRNAs, a number of miRNAs have been identified to be involved in the occurrence, development and survival of tumor $(47,48)$. Therefore, screening key miRNAs may be beneficial to further investigate their specific roles in WT. By integrating the miRNA microarray data in GSE57370 with the miRNA-sequencing data in the TCGA dataset, 29 overlapping DEMs were identified in the present study. These DEMs may serve important roles in WT.

Furthermore, TargetScan, miRTarBase and miRDB were used to predict the target genes of the DEMs and only genes identified by all three databases were further analyzed. Subsequently, 879 target genes were integrated with the aforementioned DEGs, and 19 overlapping genes were identified. A DEMs-DEGs network was constructed to reveal potential regulatory pathways by which the 16 DEMs and 19 DEGs serve their roles. In KEGG pathway analysis, two genes were revealed to be involved in the Fc gamma R-mediated phagocytosis pathway. It was demonstrated that WASF3 and MARCKSL1 were highly expressed in the tumor samples in the Yusenko Renal dataset. Based on the expression profiles of the DEMs and the miRNA-mRNA network, downregulated hsa-miR-200b and hsa-miR-429 may be the upstream regulatory elements of WASF3, and hsa-miR-30c-2 may be the regulator of MARCKSL1. It has been reported that miR-200b may inhibit the growth and motility of breast cancer cells (49). miR-429 can suppress the cell proliferation, migration and invasion of nasopharyngeal carcinoma (50). Similarly, miR-30c-2 has been demonstrated to be involved in cancer cell proliferation and apoptosis (51). Additionally, WASF3 and 


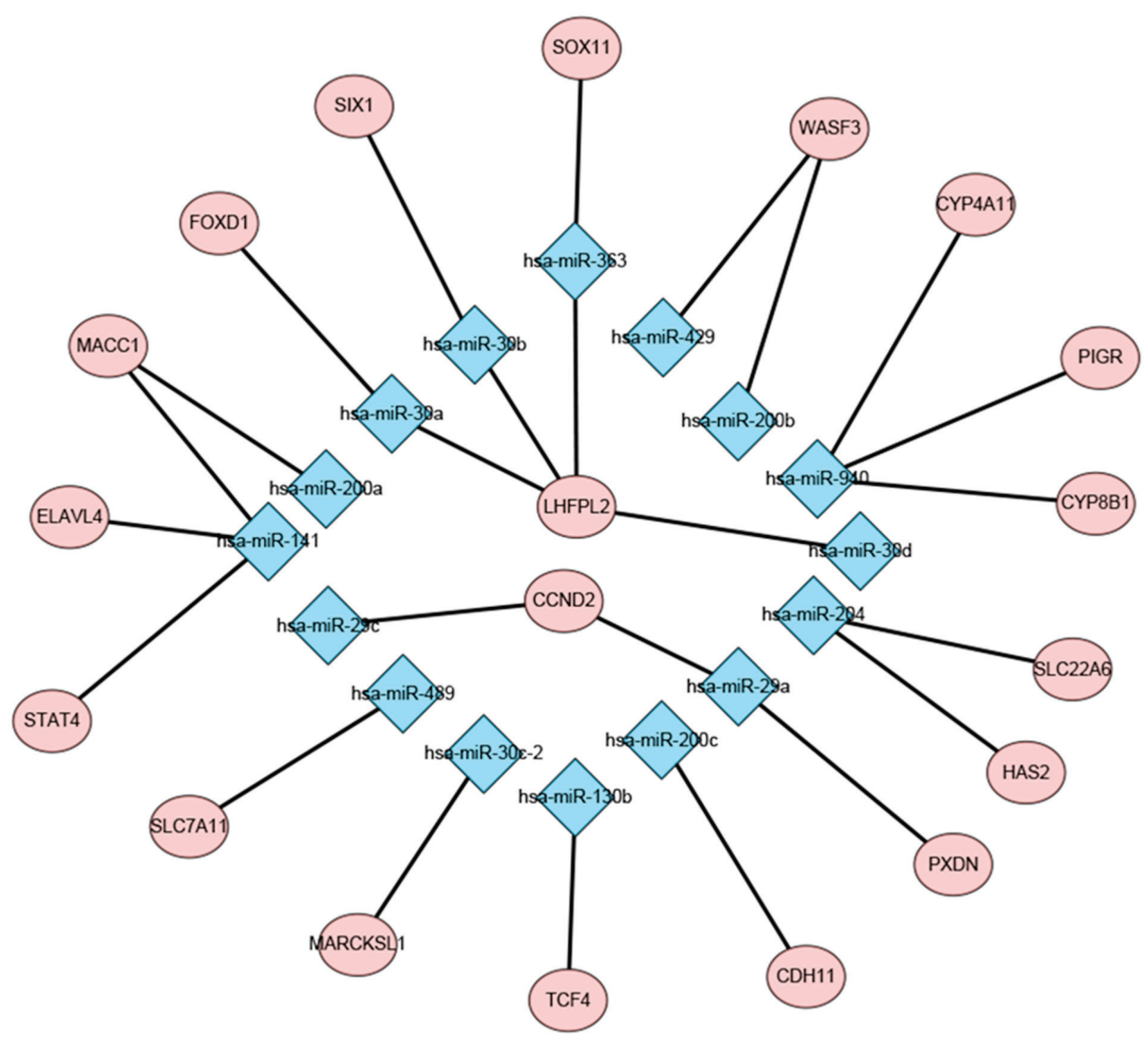

Figure 7. Construction of a potential regulatory network of differentially expressed microRNAs and differentially expressed genes. Red nodes represent genes, blue nodes represent microRNAs, and lines represent interactions. hsa-miR, homo sapiens-microRNA.
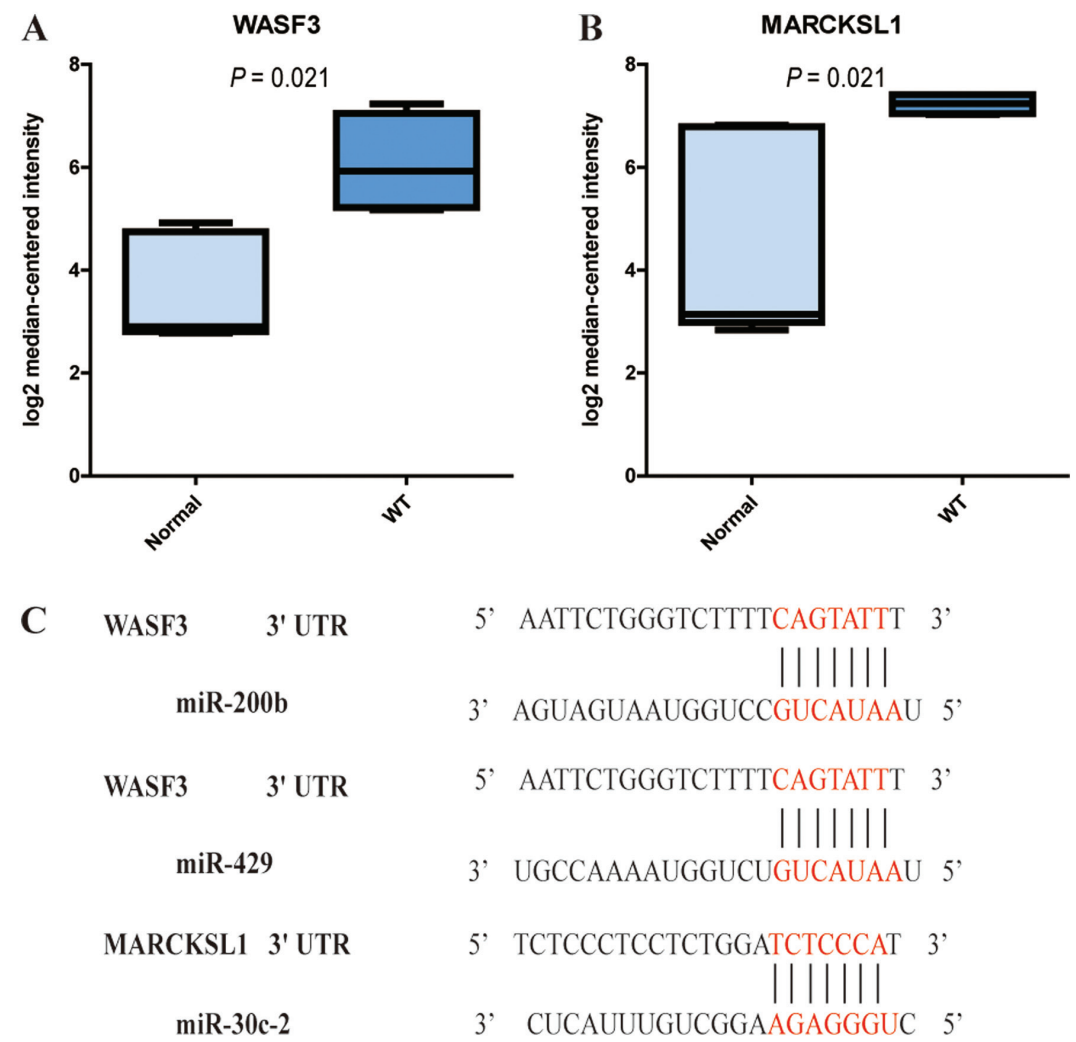

Figure 8. Validation of mRNA expression by Oncomine database analysis and prediction of microRNA-mRNA binding regions. (A) WASF3. (B) MARCKSL1. (C) miR-200b, miR-429 and miR-30c-2 binding to the 3' UTR of targets. 3' UTR, 3' untranslated region; MARCKSL1, MARCKS like 1; miR, microRNA; WASF3, Wiskott-Aldrich syndrome protein family member 3; WT, Wilms tumor. 
MARCKSL1 have been reported to be associated with malignant behaviors of certain tumor types, including bladder and breast cancer $(52,53)$. Therefore, one may speculate that the three regulatory pathways of miR-200b/WASF3, miR-429/WASF3 and miR-30c-2/MARCKSL1 may serve significant roles in WT. However, this remains to be validated by future experiments.

In the present study, five hub genes were identified, and these were associated with the cell cycle pathway and may be potential biomarkers of WT. Furthermore, the present study predicted potential miRNA-mRNA regulatory pathways by constructing an interaction network. These results may direct experimental investigations regarding the molecular mechanisms in WT.

In conclusion, the present study identified 613 DEGs and 29 DEMs by bioinformatics analysis, which may be potential biomarkers for the occurrence of WT. By screening the hub module in a PPI network and performing functional enrichment analyses, five hub genes (BUB1, BUB1B, CDC45, CCNB2 and PTTG1) associated with the cell cycle and mitosis were identified. These may serve important roles in WT. In addition, differential expression levels of these genes were verified using the Oncomine database. Furthermore, the present study predicted potential regulatory mechanisms of the DEMs and DEGs in WT, and aimed to assist further molecular biological investigations that may verify these mechanisms.

\section{Acknowledgements}

Not applicable.

\section{Funding}

The present study was supported by the National Natural Science Funding of China (grant nos. 81600514 and 81670608).

\section{Availability of data and materials}

The datasets generated and/or analyzed during the current study are available in the Gene Expression Omnibus repository (accession numbers GSE66405 and GSE57370) and TCGA repository (mRNA, https://portal.gdc.cancer.gov/reposit ory?facetTab $=$ files $\&$ filters $=\% 7 \mathrm{~B} \% 22 \mathrm{op} \% 22 \% 3 \mathrm{~A} \% 22 \mathrm{and} \% 22$ $\% 2 \mathrm{C} \% 22$ content $\% 22 \% 3 \mathrm{~A} \% 5 \mathrm{~B} \% 7 \mathrm{~B} \% 22$ op $\% 22 \% 3 \mathrm{~A} \% 22 \mathrm{in} \% 22$ $\% 2 \mathrm{C} \% 22$ content $\% 22 \% 3 \mathrm{~A} \% 7 \mathrm{~B} \% 22$ field $\% 22 \% 3 \mathrm{~A} \% 22$ cases. project.project_id $\% 22 \% 2 \mathrm{C} \% 22$ value $\% 22 \% 3 \mathrm{~A} \% 5 \mathrm{~B} \% 22 \mathrm{TA}$ RGET-WT\%22\%5D\%7D\%7D\%2C\%7B\%22op\%22\%3A\%22in $\% 22 \% 2 \mathrm{C} \% 22$ content $\% 22 \% 3 \mathrm{~A} \% 7 \mathrm{~B} \% 22$ field $\% 22 \% 3 \mathrm{~A} \% 22$ files. analysis.workflow_type $\% 22 \% 2 \mathrm{C} \% 22$ value $\% 22 \% 3 \mathrm{~A} \% 5 \mathrm{~B} \% 22 \mathrm{H}$ TSeq $\% 20-\% 20$ Counts\%22\%5D\%7D\%7D\%2C\%7B\%22op\%22 $\% 3 \mathrm{~A} \% 22 \mathrm{in} \% 22 \% 2 \mathrm{C} \% 22$ content $\% 22 \% 3 \mathrm{~A} \% 7 \mathrm{~B} \% 22$ field $\% 22 \% 3 \mathrm{~A}$ $\% 22$ files.experimental_strategy $\% 22 \% 2 \mathrm{C} \% 22$ value $\% 22 \% 3 \mathrm{~A} \% 5 \mathrm{~B}$ \%22RNA-Seq\%22\%5D\%7D\%7D\%5D\%7D; miRNA, https:// portal.gdc.cancer.gov/repository?facetTab $=$ files \&filters $=\% 7 \mathrm{~B} \% 2$ 2op $\% 22 \% 3 \mathrm{~A} \% 22$ and $\% 22 \% 2 \mathrm{C} \% 22$ content $\% 22 \% 3 \mathrm{~A} \% 5 \mathrm{~B} \% 7 \mathrm{~B} \% 2$ 2op $\% 22 \% 3 \mathrm{~A} \% 22$ in $\% 22 \% 2 \mathrm{C} \% 22$ content $\% 22 \% 3 \mathrm{~A} \% 7 \mathrm{~B} \% 22$ field $\% 22 \% 3 \mathrm{~A} \% 22$ cases.project.project_id $\% 22 \% 2 \mathrm{C} \% 22$ value $\% 22 \% 3$ A\%5B\%22TARGET-WT\%22\%5D\%7D\%7D\%2C\%7B\%22op\% $22 \% 3 \mathrm{~A} \% 22 \mathrm{in} \% 22 \% 2 \mathrm{C} \% 22$ content $\% 22 \% 3 \mathrm{~A} \% 7 \mathrm{~B} \% 22$ field $\% 22 \%$ 3A $\% 22$ files.data_category $\% 22 \% 2 \mathrm{C} \% 22$ value $\% 22 \% 3 \mathrm{~A} \% 5 \mathrm{~B} \% 22$ Transcriptome $\% 20$ Profiling $\% 22 \% 5 \mathrm{D} \% 7 \mathrm{D} \% 7 \mathrm{D} \% 2 \mathrm{C} \% 7 \mathrm{~B} \% 22 \mathrm{op}$ $\% 22 \% 3 \mathrm{~A} \% 22$ in $\% 22 \% 2 \mathrm{C} \% 22$ content $\% 22 \% 3 \mathrm{~A} \% 7 \mathrm{~B} \% 22$ field $\% 22$
$\% 3 \mathrm{~A} \% 22$ files.data_type $\% 22 \% 2 \mathrm{C} \% 22$ value $\% 22 \% 3 \mathrm{~A} \% 5 \mathrm{~B} \% 22 \mathrm{~m}$ iRNA\%20Expression\%20Quantification\%22\%5D\%7D\%7D\%2C $\% 7 \mathrm{~B} \% 22$ op $\% 22 \% 3 \mathrm{~A} \% 22 \mathrm{in} \% 22 \% 2 \mathrm{C} \% 22$ content $\% 22 \% 3 \mathrm{~A} \% 7 \mathrm{~B} \%$ 22field $\% 22 \% 3 \mathrm{~A} \% 22$ files.experimental_strategy $\% 22 \% 2 \mathrm{C} \% 22 \mathrm{val}$ ue $\% 22 \% 3 \mathrm{~A} \% 5 \mathrm{~B} \% 22 \mathrm{miRNA}-\mathrm{Seq} \% 22 \% 5 \mathrm{D} \% 7 \mathrm{D} \% 7 \mathrm{D} \% 5 \mathrm{D} \% 7 \mathrm{D}$ $\&$ searchTableTab=files). The remaining datasets used and/or analyzed during the current study are available from the corresponding author on reasonable request.

\section{Authors' contributions}

WW, MT and WZ designed the study and contributed to language editing and proofreading. RL, ZQ, YW, LZ and XG retrieved and processed the data. $\mathrm{LZ}$ and $\mathrm{XZ}$ analyzed the data. $\mathrm{LZ}$ and $\mathrm{XG}$ wrote and edited the manuscript, and prepared figures and tables. All authors read and approved the final manuscript.

\section{Ethics approval and consent to participate}

Not applicable.

\section{Patient consent for publication}

Not applicable.

\section{Competing interests}

The authors declare that they have no competing interests.

\section{References}

1. Charlton J, Pavasovic V and Pritchard-Jones K: Biomarkers to detect Wilms tumors in pediatric patients: Where are we now? Future Oncol 11: 2221-2234, 2015.

2. Scott RH, Stiller CA, Walker L and Rahman N: Syndromes and constitutional chromosomal abnormalities associated with Wilms tumour. J Med Genet 43: 705-715, 2006.

3. Hung IJ, Chang WH, Yang CP, Jaing TH, Liang DC, Lin KH, Lin DT, Hsiao CC, Hsieh YL, Chen JS, et al: Epidemiology, clinical features and treatment outcome of Wilms' tumor in Taiwan: A report from Taiwan pediatric oncology group. J Formos Med Assoc 103: 104-111, 2004.

4. Al-Hussain T, Ali A and Akhtar M: Wilms tumor: An update. Adv Anat Pathol 21: 166-173, 2014.

5. Segers H, Kersseboom R, Alders M, Pieters R, Wagner A and van den Heuvel-Eibrink MM: Frequency of WT1 and 11p15 constitutional aberrations and phenotypic correlation in childhood Wilms tumour patients. Eur J Cancer 48: 3249-3256, 2012.

6. Fukuzawa R, Holman SK, Chow CW, Savarirayan R, Reeve AE and Robertson SP: WTX mutations can occur both early and late in the pathogenesis of Wilms tumour. J Med Genet 47: 791-794, 2010.

7. Li CM, Kim CE, Margolin AA, Guo M, Zhu J, Mason JM, Hensle TW, Murty VV, Grundy PE, Fearon ER, et al: CTNNB1 mutations and overexpression of Wnt/beta-catenin target genes in WT1-mutant Wilms' tumors. Am J Pathol 165: 1943-1953, 2004.

8. Haber DA, Buckler AJ, Glaser T, Call KM, Pelletier J, Sohn RL, Douglass EC and Housman DE: An internal deletion within an $11 \mathrm{p} 13$ zinc finger gene contributes to the development of Wilms' tumor. Cell 61: 1257-1269, 1990.

9. Scott RH, Murray A, Baskcomb L, Turnbull C, Loveday C, Al-Saadi R, Williams R, Breatnach F, Gerrard M, Hale J, et al: Stratification of Wilms tumor by genetic and epigenetic analysis. Oncotarget 3: 327-335, 2012.

10. Fu W, Zhuo Z, Hua RX, Fu K, Jia W, Zhu J, Zhang J, Cheng J, Zhou H, Xia H, et al: Association of KRAS and NRAS gene polymorphisms with Wilms tumor risk: A four-center case-control study. Aging (Albany NY) 11: 1551-1563, 2019. 
11. Diets IJ, Hoyer J, Ekici AB, Popp B, Hoogerbrugge N, van Reijmersdal SV, Bhaskaran R, Hadjihannas M, Vasileiou G, Thiel CT, et al: TRIM28 haploinsufficiency predisposes to Wilms tumor. Int J Cancer 145: 941-951, 2019.

12. Polosukhina D, Love HD, Correa H, Su Z, Dahlman KB, Pao W, Moses HL, Arteaga CL, Lovvorn HN III, Zent R and Clark PE: Functional KRAS mutations and a potential role for PI3K/AKT activation in Wilms tumors. Mol Oncol 11: 405-421, 2017.

13. Bartel DP: MicroRNAs: Genomics, biogenesis, mechanism, and function. Cell 116: 281-297, 2004.

14. Volinia S, Calin GA, Liu CG, Ambs S, Cimmino A, Petrocca F, Visone R, Iorio M, Roldo C, Ferracin M, et al: A microRNA expression signature of human solid tumors defines cancer gene targets. Proc Natl Acad Sci USA 103: 2257-2261, 2006.

15. Liu GL, Yang HJ, Liu B and Liu T: Effects of microRNA-19b on the proliferation, apoptosis, and migration of Wilms' tumor cells via the PTEN/PI3K/AKT signaling pathway. J Cell Biochem 118: 3424-3434, 2017.

16. Zhu S, Zhang L, Zhao Z, Fu W, Fu K, Liu G and Jia W: MicroRNA92a-3p inhibits the cell proliferation, migration and invasion of Wilms tumor by targeting NOTCH1. Oncol Rep 40: 571-578, 2018.

17. Vogelstein B, Papadopoulos N, Velculescu VE, Zhou S, Diaz LA Jr and Kinzler KW: Cancer genome landscapes. Science 339: 1546-1558, 2013.

18. Guo Y, Bao Y, Ma M and Yang W: Identification of key candidate genes and pathways in colorectal cancer by integrated bioinformatical analysis. Int J Mol Sci 18: E722, 2017.

19. Ludwig N, Werner TV, Backes C, Trampert P, Gessler M, Keller A, Lenhof HP, Graf N and Meese E: Combining miRNA and mRNA expression profiles in Wilms tumor subtypes. Int J Mol Sci 17: 475, 2016.

20. Wegert J, Ishaque N, Vardapour R, Geörg C, Gu Z, Bieg M, Ziegler B, Bausenwein S, Nourkami N, Ludwig N, et al: Mutations in the SIX1/2 pathway and the DROSHA/DGCR8 miRNA microprocessor complex underlie high-risk blastemal type Wilms tumors. Cancer Cell 27: 298-311, 2015.

21. Tomczak K, Czerwińska P and Wiznerowicz M: The cancer genome atlas (TCGA): An immeasurable source of knowledge. Contemp Oncol (Pozn) 19: A68-A77, 2015.

22. Diboun I, Wernisch L, Orengo CA and Koltzenburg M: Microarray analysis after RNA amplification can detect pronounced differences in gene expression using limma. BMC Genomics 7: 252, 2006.

23. Robinson MD, McCarthy DJ and Smyth GK: EdgeR: A Bioconductor package for differential expression analysis of digital gene expression data. Bioinformatics 26: 139-140, 2010.

24. Dennis G Jr, Sherman BT, Hosack DA, Yang J, Gao W, Lane HC and Lempicki RA: DAVID: Database for annotation, visualization, and integrated discovery. Genome Biol 4: P3, 2003.

25. Szklarczyk D, Franceschini A, Wyder S, Forslund K, Heller D, Huerta-Cepas J, Simonovic M, Roth A, Santos A, Tsafou KP, et al: STRING v10: Protein-protein interaction networks, integrated over the tree of life. Nucleic Acids Res 43: D447-D452, 2015

26. Smoot ME, Ono K, Ruscheinski J, Wang PL and Ideker T: Cytoscape 2.8: New features for data integration and network visualization. Bioinformatics 27: 431-432, 2011.

27. Bader GD and Hogue CW: An automated method for finding molecular complexes in large protein interaction networks. BMC Bioinformatics 4: 2, 2003.

28. Yusenko MV, Kuiper RP, Boethe T, Ljungberg B, van Kessel AG and Kovacs G: High-resolution DNA copy number and gene expression analyses distinguish chromophobe renal cell carcinomas and renal oncocytomas. BMC Cancer 9: 152, 2009.

29. Agarwal V, Bell GW, Nam JW and Bartel DP: Predicting effective microRNA target sites in mammalian mRNAs. Elife 4: 05005, 2015.

30. Chou CH, Chang NW, Shrestha S, Hsu SD, Lin YL, Lee WH, Yang CD, Hong HC, Wei TY, Tu SJ, et al: miRTarBase 2016: Updates to the experimentally validated miRNA-target interactions database. Nucleic Acids Res 44: D239-D247, 2016.

31. Wong N and Wang X: miRDB: An online resource for microRNA target prediction and functional annotations. Nucleic Acids Res 43: D146-D152, 2015.

32. Pierce J, Murphy AJ, Panzer A, de Caestecker C, Ayers GD, Neblett D, Saito-Diaz K, de Caestecker M and Lovvorn HN III: SIX2 effects on wilms tumor biology. Transl Oncol 7: 800-811, 2014

33. Yap LW, Brok J and Pritchard-Jones K: Role of CD56 in normal kidney development and Wilms tumorigenesis. Fetal Pediatr Pathol 36: 62-75, 2017.

34. Nordenskjöld A, Friedman E, Sandstedt B, Söderhäll S and Anvret M: Constitutional and somatic mutations in the WT1 gene in Wilms' tumor patients. Int J Cancer 63: 516-522, 1995.
35. Alexandrescu S, Akhavanfard S, Harris MH and Vargas SO: Clinical, pathologic, and genetic features of Wilms tumors with WTX gene mutation. Pediatr Dev Pathol 20: 105-111, 2017.

36. Deng C, Dai R, Li X and Liu F: Genetic variation frequencies in Wilms' tumor: A meta-analysis and systematic review. Cancer Sci 107: 690-699, 2016.

37. Ooms AH, Gadd S, Gerhard DS, Smith MA, Guidry Auvil JM, Meerzaman D, Chen QR, Hsu CH, Yan C, Nguyen C, et al: Significance of TP53 mutation in Wilms tumors with diffuse anaplasia: A report from the children's oncology group. Clin Cancer Res 22: 5582-5591, 2016.

38. Dominguez-Brauer C, Thu KL, Mason JM, Blaser H, Bray MR and Mak TW: Targeting mitosis in cancer: Emerging strategies. Mol Cell 60: 524-536, 2015.

39. Alimbetov D, Askarova S, Umbayev B, Davis T and Kipling D: Pharmacological targeting of cell cycle, apoptotic and cell adhesion signaling pathways implicated in chemoresistance of cancer cells. Int J Mol Sci 19: E1690, 2018.

40. Knudsen ES, Pruitt SC, Hershberger PA, Witkiewicz AK and Goodrich DW: Cell cycle and beyond: Exploiting new RB1 controlled mechanisms for cancer therapy. Trends Cancer 5: 308-324, 2019.

41. Xu B, Xu T, Liu H, Min Q, Wang S and Song Q: miR-490-5p suppresses cell proliferation and invasion by targeting BUB1 in hepatocellular carcinoma cells. Pharmacology 100: 269-282, 2017.

42. Fu X, Chen G, Cai ZD, Wang C, Liu ZZ, Lin ZY, Wu YD, Liang YX, Han ZD, Liu JC and Zhong WD: Overexpression of BUB1B contributes to progression of prostate cancer and predicts poor outcome in patients with prostate cancer. Onco Targets Ther 9: 2211-2220, 2016.

43. Stahl D, Braun M, Gentles AJ, Lingohr P, Walter A, Kristiansen G and Gütgemann I: Low BUB1 expression is an adverse prognostic marker in gastric adenocarcinoma. Oncotarget 8: 76329-76339, 2017.

44. Ocaña A, Pérez-Peña J, Díez-González L, Sánchez-Corrales V, Templeton A, Seruga B, Amir E and Pandiella A: Transcriptomic analyses identify association between mitotic kinases, PDZ-binding kinase and BUB1, and clinical outcome in breast cancer. Breast Cancer Res Treat 156: 1-8, 2016.

45. Wei YT, Guo DW, Hou XZ and Jiang DQ: miRNA-223 suppresses FOXO1 and functions as a potential tumor marker in breast cancer. Cell Mol Biol (Noisy-le-grand) 63: 113-118, 2017.

46. Sharma P and Sharma R: miRNA-mRNA crosstalk in esophageal cancer: From diagnosis to therapy. Crit Rev Oncol Hematol 96: 449-462, 2015.

47. Zhang D, Zhao L, Shen Q, Lv Q, Jin M, Ma H, Nie X, Zheng X, Huang S, Zhou P, et al: Down-regulation of KIAA1199/CEMIP by miR-216a suppresses tumor invasion and metastasis in colorectal cancer. Int J Cancer 140: 2298-2309, 2017.

48. Jia AY, Castillo-Martin M, Bonal DM, Sánchez-Carbayo M, Silva JM and Cordon-Cardo C: MicroRNA-126 inhibits invasion in bladder cancer via regulation of ADAM9. Br J Cancer 110: 2945-2954, 2014

49. Lv Z, Wei J, You W, Wang R, Shang J, Xiong Y, Yang H, Yang X and Fu Z: Disruption of the c-Myc/miR-200b-3p/PRDX2 regulatory loop enhances tumor metastasis and chemotherapeutic resistance in colorectal cancer. J Transl Med 15: 257, 2017.

50. Wang Z, Zhu Z, Lin Z, Luo Y, Liang Z, Zhang C, Chen J and Peng P: miR-429 suppresses cell proliferation, migration and invasion in nasopharyngeal carcinoma by downregulation of TLN1. Cancer Cell Int 19: 115, 2019.

51. Tang CT, Liang Q, Yang L, Lin XL, Wu S, Chen Y, Zhang XT, Gao YJ and Ge ZZ: RAB31 targeted by miR-30c-2-3p regulates the GLI1 signaling pathway, affecting gastric cancer cell proliferation and apoptosis. Front Oncol 8: 554, 2018.

52. Jin H, Xie Q, Guo X, Xu J, Wang A, Li J, Zhu J, Wu XR, Huang $\mathrm{H}$ and Huang C: p63 $\alpha$ protein up-regulates heat shock protein 70 expression via $\mathrm{E} 2 \mathrm{~F} 1$ transcription factor 1, promoting Wasf3/Wave3/MMP9 signaling and bladder cancer invasion. J Biol Chem 292: 15952-15963, 2017.

53. Kim BR, Dong SM, Seo SH, Lee JH, Lee JM, Lee SH and Rho SB: Lysyl oxidase-like 2 (LOXL2) controls tumor-associated cell proliferation through the interaction with MARCKSL1. Cell Signal 26: 1765-1773, 2014. 